\title{
Reference gene validation for qPCR in rat carotid body during postnatal development
}

Insook Kim', Dongjin Yang ${ }^{1}$, Xinyu Tang ${ }^{2}$ and John L Carroll ${ }^{1 *}$

\begin{abstract}
Background: The carotid bodies are the main arterial oxygen chemoreceptors in mammals. Afferent neural output from the carotid bodies to brainstem respiratory and cardiovascular nuclei provides tonic input and mediates important protective responses to acute and chronic hypoxia. It is widely accepted that the selection of reference genes for mRNA normalization in quantitative real-time PCR must be validated for a given tissue and set of conditions. This is particularly important for studies in carotid body during early postnatal maturation as the arterial oxygen tension undergoes major changes from fetal to postnatal life, which may affect reference gene expression. In order to determine the most stable and suitable reference genes for the study of rat carotid body during development, six commonly used reference genes, $\beta$-actin, RPII (RNA polymerase II), PPIA (peptidyl-proyl-isomerase A), TBP (TATA-box binding protein), GAPDH, and 18s rRNA, were evaluated in two age groups (P0-1 and P14-16) under three environmental oxygen conditions (normoxia, chronic hypoxia and chronic hyperoxia) using the three most commonly used software programs, geNorm, NormFinder and BestKeeper.
\end{abstract}

Findings: The three programs produced similar results but the reference gene rankings were not identical between programs or experimental conditions. Overall, 18s rRNA was the least stable reference gene for carotid body and, when hyperoxia and/or hypoxia conditions were included, actin was similarly unstable.

Conclusions: Reference or housekeeping gene expression for QPCR studies of carotid body during postnatal development may vary with developmental stage and environmental conditions. Selection of the best reference gene or combination of reference genes for carotid body development studies should take environmental conditions into account. Two commonly used reference genes, 18s rRNA and actin, may be unsuitable for studies of carotid body maturation, especially if the study design includes altered oxygen conditions.

\section{Findings Introduction}

Mammals have evolved a complex oxygen sensing system that links rapidly responding peripheral arterial $\mathrm{PO}_{2}$ sensors, the carotid body (CB) chemoreceptors, with central respiratory motor output and cardiovascular reflexes. Afferent neural output from the carotid bodies is transmitted via the carotid sinus nerves (CSN) to brainstem respiratory and cardiovascular nuclei, which control ventilatory, heart rate and blood pressure responses to hypoxia [1] and mediate other important defenses during hypoxic stress [2-6]. In all species

\footnotetext{
* Correspondence: carrolljohnl@uams.edu

'University of Arkansas for Medical Sciences, Department of Pediatrics, Division of Pulmonary Medicine, Arkansas Children's Hospital Research Institute, Little Rock, Arkansas, USA

Full list of author information is available at the end of the article
}

studied to date, $\mathrm{CB}$ responsiveness to hypoxia is low in newborns and increases with age $[7,8]$.

Glomus cells (or "type- 1 cells"), the $\mathrm{O}_{2}$-sensing cells of the $\mathrm{CB}$, are arranged in clusters with apposed nerve terminals of the carotid sinus nerve, whose cell bodies are located in the petrosal ganglion (PG) [9]. Studies of rat glomus cells from our laboratory demonstrate that the magnitude of hypoxia-induced cell membrane depolarization, the intracellular calcium response $\left(\left[\mathrm{Ca}^{2+}\right]_{\mathrm{i}}\right)$ to hypoxia and the magnitude of an $\mathrm{O}_{2}$-sensitive background $\mathrm{K}^{+}$current increase with age from birth (postnatal day 0: P0) to postnatal day 14-21 (P14-21) [10-12]. The mechanisms are unknown but may involve postnatal changes in glomus cell ion channel expression. Therefore, studies of ion channel expression are crucial to understanding the mechanisms of $\mathrm{CB}$ glomus cell $\mathrm{O}_{2}$ sensing and its postnatal maturation.

\section{() Biomed Central}


Developmental studies of gene expression typically employ relative quantification by qPCR, where normalization against an internal control gene is commonly used. The use of internal control genes (reference genes) assumes that their expression is invariant in the cells or tissue under study and with experimental treatments. Developmental studies, in addition, assume that reference genes for qPCR do not change with stage of development or ambient conditions. However, numerous studies show that commonly used reference genes, such as $\beta$-actin, GAPDH or 18s rRNA, are not constant between different developmental stages and different experimental conditions [13-20]. Normalization of the data with unstable reference genes can result in misleading or false conclusions.

It has become widely accepted that the selection of reference genes must be validated for a given tissue and set of conditions [21] and the use of multiple reference genes is viewed as a more robust, accurate and reliable approach to normalization [21-24]. This approach can be facilitated by the use of tools such as geNorm [22], NormFinder [25] and BestKeeper [26], which allow selection of the most stable reference genes and determination of the best combination to use for normalization for a given tissue and set of conditions.

Fetal arterial $\mathrm{PO}_{2}$ in mammals is about $23-28 \mathrm{mmHg}$ and rises $\sim 4$ fold within the first two hours after birth $[27,28]$, raising the additional possibility that oxygendependent gene expression may change during the first days or weeks after birth [29,30]. Specifically, oxygen tension may affect the expression of reference genes in a tissue-specific manner [13,31], suggesting that candidate reference genes for normalization should be validated not only for a given tissue but also for oxygen conditions that may affect expression and over the time frame when such changes may occur.

In the present study, six candidate reference genes were evaluated using three reference gene selection tools in whole rat carotid bodies during a crucial developmental period (P0 to P16) and under conditions of peri- and postnatal normoxia, hypoxia and hyperoxia. Results indicate that actin and 18s rRNA, housekeeping genes commonly used for qPCR normalization, were among the least stable reference genes under most conditions.

\section{Methods}

\section{Overview of study design}

Six commonly used reference genes, $\beta$-actin, RPII (RNA polymerase II), PPIA (peptidyl-proyl-isomerase A), TBP (TATA-box binding protein), GAPDH, and 18s rRNA, were validated using geNorm [22], NormFinder [25] and BestKeeper [26] for two age groups (P0-1 and P14-16) under three environmental oxygen conditions (normoxia, chronic hypoxia and chronic hyperoxia). This yielded four groups as follows: age P0-1, normoxia (N1), age P14-16, normoxia (N14), age P14-16, chronic hyperoxia treated (Hyper14), and age P14-16, chronic hypoxia treated (Hypo14). To reduce the inter-assay variations, all six reference genes were run with qPCR with all four sets of samples; N1, N14, Hyper14, and Hypo14. In order to evaluate $\mathrm{CB}$ reference gene stability under conditions relevant to postnatal development we performed the analysis, with geNorm, NormFinder and BestKeeper, using four combinations of the conditions, as follows: N1+N14 (development), N14+Hyper14 (chronic hyperoxia during development), N14+Hypo14 (chronic hypoxia during development) and N1+N14 + Hyper14+Hypo14 (development + altered environmental condition). The procedures used in this study were approved by the Institutional Animal Care and Use Committee of the University of Arkansas for Medical Sciences.

\section{Chronic Hyperoxia or Hypoxia Treatment}

For chronic hyperoxia or hypoxia treatment, timed-pregnant Sprague-Dawley rats were placed in a controlled atmosphere chamber 1-2 days prior to expected delivery and were allowed to give birth in the chamber (OxyCycler Model A84XOV, BioSpherix, Redfield, NY). The system continuously monitors and maintains a preset oxygen level, and $\mathrm{O}_{2} / \mathrm{CO}_{2}$ tensions are recorded continuously (AnaWin software). The chambers employ a controlled leak to the room environment in order to limit $\mathrm{CO}_{2}$ /humidity buildup. For chronic hyperoxia and hypoxia treatment, rats were exposed to $0.60 \mathrm{FiO}_{2}$ or $0.12 \mathrm{FiO}_{2}$, respectively. Pups and dams were maintained in the chamber until use at P14-16.

\section{Isolation of Rat CB and tRNA Extraction}

Carotid bodies (CB) were isolated from rats age P0-1 (N1), P14-16 (N14), P14-16 male and female rats exposed continuously to hyperoxia $\left(60 \% \mathrm{O}_{2}\right)$ from birth (Hyper14), and P14-16 rats exposed to hypoxia (12\% $\mathrm{O}_{2}$ ) from birth (Hypo14) as described previously [12]. For $\mathrm{CB}$ isolation, rats were anesthetized with isoflurane and decapitated under deep surgical anesthesia. The carotid bifurcations were dissected and placed in ice-cold phosphate buffered saline (PBS). The carotid bodies were then removed from the bifurcations and placed in cold sterile PBS. Isolated CBs were placed into a $1.5 \mathrm{ml}$ centrifuge tube, washed with ice-cold PBS, and stored in RNAlater stabilization reagent (Qiagen) at $-80^{\circ} \mathrm{F}$. Frozen collected CBs were processed to extract the Total RNA (tRNA) using AquaPure RNA isolation kit (Bio-Rad). tRNA was extracted from $\sim 50$ frozen $C B s$ and the tRNA pellet was reconstituted in 10-16 $\mu$ l of hydration solution depending on size of isolated $\mathrm{CB}$. The 
concentration of extracted tRNA was measured by spectrophotometer (SmartSpec Plus, Bio-Rad) at $260 \mathrm{~nm}$. Purity of tRNA was determined as the $260 \mathrm{~nm} / 280 \mathrm{~nm}$ ratio with expected values between 1.8 and 2 .

Extracted tRNA were treated with RQ1 RNA-free DNase (Promega) and estimated $1 \mu \mathrm{g}$ of pure tRNA ran for cDNA sysnthesis $(20 \mu \mathrm{l})$ by using iScript cDNA synthesis kit (Bio-Rad). cDNA at 5X dilution were run using qPCR in triplicate. The six putative reference genes, $\beta$-actin, RPII (RNA polymerase II), PPIA (peptidyl-proyl-isomerase A), TBP (TATA-box binding protein), GAPDH, and 18s rRNA, were evaluated using qPCR. All six reference genes were tested with cDNA synthesized from N1, N14, Hyper14, and Hypo14 on the same plate to reduce inter-assay variations.

\section{Quantitative Real Time RT-PCR (qPCR)}

Primers for reference genes were designed by using Beacon Designer 2.0; PPIA, TBP, RPII, $\beta$-actin, GAPDH, 18s rRNA, TASK-1, TASK-2 and TASK-3 (Table 1). Designed primers were ordered from Integrated DNA Technologies (IDT, Coraville, IA) and tested on cDNA from positive control tissues prior to testing on cDNA of CB. The PCR efficiency of each primer pair was tested with the serial dilution of cDNA prepared with N14 CB in triplicate (Table 1). The real-time PCR efficiency rate $(\mathrm{E})$ in the exponential phase was calculated according to the following equation [32]:

$$
\mathrm{E}=10[-1 / \text { slope }]-1
$$

To exclude genomic DNA contamination, tRNA was treated with RQ1 RNase-free DNase (Promega) as described above (tRNA extraction methods) and cDNA was synthesized using iScript cDNA synthesis kit (BioRad). To check for DNA contamination on newly made tRNA, cDNA without reverse transcriptase (-RT) was synthesized and tested prior to use. To prevent false detection with the qPCR, a no-template-control (NTC) was tested on every run for each primer set and the melting curve was checked.

Real time PCR using SYBR green technology was performed on an iCycler iQ real-time detection system in 96-well microtitre plates using a final volume of $20 \mu \mathrm{l}$ (Bio-Rad). SYBR Green Supermix (Bio-Rad and Applied Biosystems) and $0.1 \mu \mathrm{M}$ of primers were mixed with DNAse and RNase-free water to make the $9 / 10^{\text {th }}$ of the total reaction volume and $1 / 10^{\text {th }}$ of cDNA was added into the mixture. The following amplification program was used: after 5 min of denaturation at $95^{\circ} \mathrm{C}, 50$ cycles of real time PCR with 2-step amplification were performed consisting of $15 \mathrm{~s}$ at $95^{\circ} \mathrm{C}$ for denaturation, $45 \mathrm{~s}$ at $60^{\circ} \mathrm{C}$ for annealing and $1 \mathrm{~min}$ at $95^{\circ} \mathrm{C}$ for polymerase elongation. In each qPCR run, all six reference genes were run on all four conditions, N1, N14, Hyper 14, and Hypo 14, in one 96 well PCR plate simultaneously. All samples were amplified in triplicate and the mean was obtained for further calculation. $C_{\mathrm{T}}$ values of 50 were excluded from further mathematical calculation, because 50 represents no quantitative information of the RNA amount, but only the end of the PCR run.

Table 1 Information on the primers used for real time PCR

\begin{tabular}{|c|c|c|c|c|c|}
\hline Gene & Accession \# & & Primers & Product Size (bp) & Efficiency Rate (E) \\
\hline \multirow[t]{2}{*}{ PPIA } & NM_017101 & $\mathrm{F}$ & GTCAACCCCACCGTGTTCTTC & 133 & 1.93 \\
\hline & & $\mathrm{R}$ & ATCCTTTCTCCCCAGTGCTCAG & & \\
\hline \multirow[t]{2}{*}{ TBP } & NM_001004198 & $\mathrm{F}$ & ACCGTGAATCTTGGCTGTAAAC & 123 & 2.06 \\
\hline & & $\mathrm{R}$ & CGCAGTTGTTCGTGGCTCTC & & \\
\hline \multirow[t]{2}{*}{ RPII } & AB017711 & $\mathrm{F}$ & GGCTCTCCAGATTGCGATGTG & 124 & 1.93 \\
\hline & & $\mathrm{R}$ & CAGGTAACGGCGAATGATGATG & & \\
\hline \multirow[t]{2}{*}{$\beta$-actin } & NM_031144 & $\mathrm{F}$ & CAGGGTGTGATGGTGGGTATGG & 115 & 2.03 \\
\hline & & $\mathrm{R}$ & AGTTGGTGACAATGCCGTGTTC & & \\
\hline \multirow[t]{2}{*}{ GAPDH } & NM_017008 & $\mathrm{F}$ & CAAGTTCAACGGCACAGTCAAG & 123 & 1.91 \\
\hline & & $\mathrm{R}$ & ACATACTCAGCACCAGCATCAC & & \\
\hline \multirow[t]{2}{*}{$18 \mathrm{~s}$} & X01117 & $\mathrm{F}$ & CACGGGTGACGGGGAATCAG & 105 & 2.03 \\
\hline & & $\mathrm{R}$ & CGGGTCGGGAGTGGGTAATTTG & & \\
\hline \multirow[t]{2}{*}{ TASK-1 } & NM_033376 & $\mathrm{F}$ & GCAGAAGCCGCAGGAGTTG & 126 & 2 \\
\hline & & $\mathrm{R}$ & GCCCGCACAGTTGGAGATTTAG & & \\
\hline \multirow[t]{2}{*}{ TASK-2 } & AM229406 & $\mathrm{F}$ & ACGCCCTCTACCGCTACTITG & 129 & 2.12 \\
\hline & & $\mathrm{R}$ & GCCGCCTCCTCCTCTTCTTG & & \\
\hline \multirow[t]{2}{*}{ TASK-3 } & NM_053405 & $\mathrm{F}$ & CGGTGCCTTCCTCAATCTTGTG & 144 & 1.8 \\
\hline & & $\mathrm{R}$ & TGGTGCCTCTTGCGACTCTG & & \\
\hline
\end{tabular}

Nucleotide sequences for the primers, size of PCR products, and PCR amplification efficiency rate of each primer set. All the genes are from rat origin. The realtime PCR efficiency rate $(E)$ in exponential phase was calculated according to the equation: $E=10[-1 /$ slope] [32]. 


\section{Data analysis}

Reference gene ranking and selection of best combination of multiple reference genes

Three popular software programs, geNorm [22], NormFinder [25] and BestKeeper [26], were used to evaluate or validate the best reference genes for use during $C B$ development. In general, they are based on the principle that the expression of reference genes should be the same under all experimental conditions and cell types studied. geNorm measures the variation between any two candidate control genes as the standard deviation of (log-transformed) control gene ratios. Each candidate reference gene is assigned a stability measure $(M)$ by comparing it (in a pairwise fashion) with each other reference gene candidate. The candidate genes with the most stable expression have the lowest $M$. The genes are then ranked, using stepwise exclusion of the least stable genes. NormFinder [25] uses a model-based approach to estimate overall reference gene stability but also considers variations between sample subgroups. BestKeeper [26] uses repeated pair-wise correlation analysis to determine the optimal reference genes. For relative gene quantification, REST 384 or REST2009 were used [33].

\section{Statistical Method for Rank Aggregation}

These three programs, geNorm, NormFinder and BestKeeper, have been previously reported to yield different rankings of reference genes [34]. As they use different approaches to evaluating reference gene stability [34], they would not be expected to yield identical results. Therefore, weighted rank aggregation was performed to combine the ordered lists of genes produced by geNorm, NormFinder, and BestKeeper to a consensus rank of genes. The M-values obtained from geNorm, variability measurements from NormFinder, and the coefficients of correlation from BestKeeper were used as weights in the aggregation process. Brute force method was used to enumerate all possible candidate lists and find the one with the minimum Spearman footrule distance using the BruteAggreg function [35]. Although it is recommended that the Cross-Entropy Monte Carlo algorithm should be used when the size of the ranking list is relatively larger than 10, it was used additionally to validate the consensus rank of genes resulting from the brute force approach. The two methods yielded consistent ranking lists, demonstrating that the consensus ranks of genes were robust to the methods used. The rank aggregations were conducted with $\mathrm{R}$ software version 2.11.1 ( $\mathrm{R}$ Development Core Team, 2009).

\section{Results}

All six reference genes, PPIA, TBP, RPII, $\beta$-actin, GAPDH, and 18s rRNA, were detected from all tested CB samples (Figure 1). The median expression levels

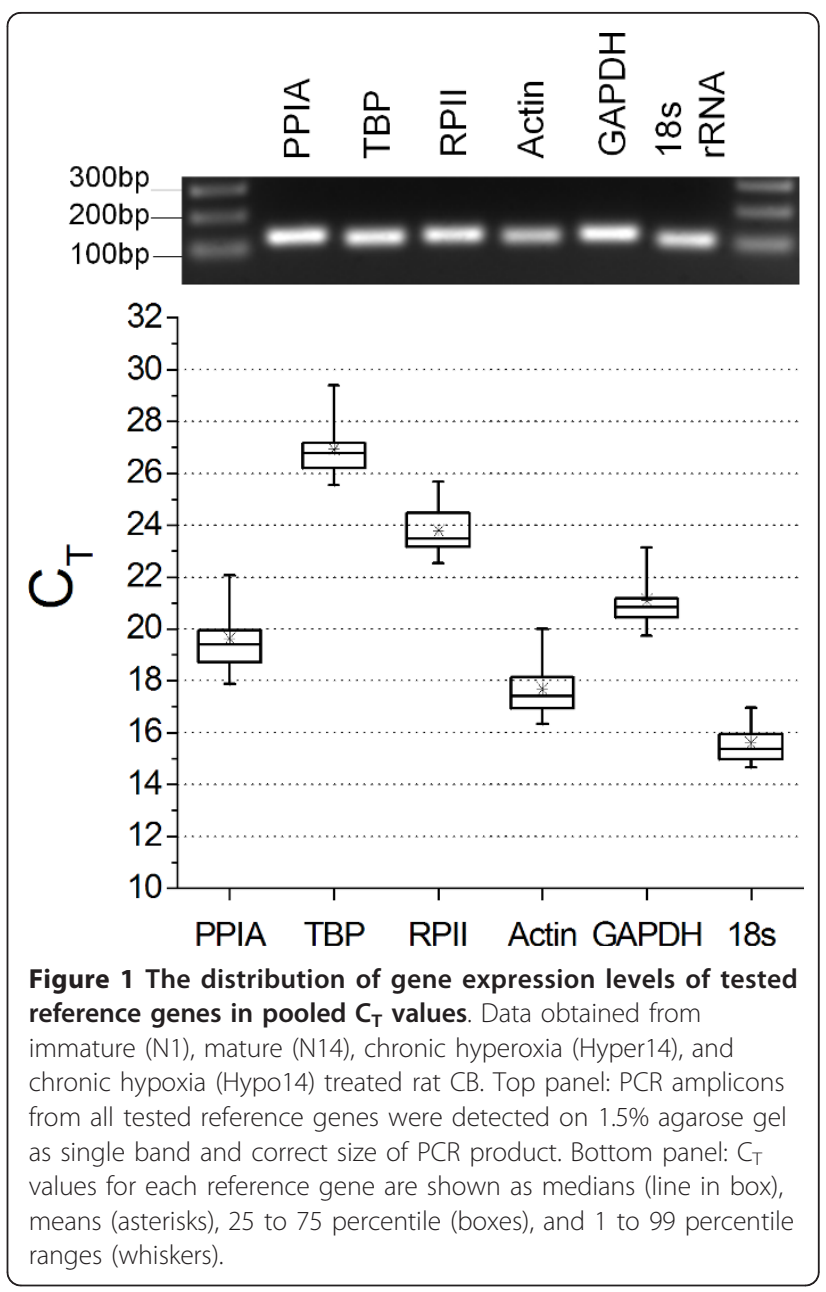

$\left(C_{T}\right.$ value $)$ for each validated reference gene are shown in Figure 1. For 18s rRNA, cDNA was diluted $125 \mathrm{x}$ to fit its $C_{T}$ value into a reasonable $C_{T}$ range. TBP showed the lowest expression level among 6 reference genes, but its $C_{T}$ values were at a reasonable detection level for SYBR green real time PCR.

Reference genes during $\mathrm{CB}$ development in normoxia, chronic hyperoxia and chronic hypoxia treatment were evaluated with extracted RNA in four combinations as follows: N1+N14, N14+Hyper14, N14+Hypo14, or N1 $+\mathrm{N} 14+$ Hyper14+Hypo14. geNorm found PPIA and TBP or RPII and TBP to be the most stable reference gene combinations (Table 2). 18s rRNA was the least stable in all groups according to geNorm (Table 2). geNorm calculates an expression stability value, termed " $M$ ", which is highest for the least stable gene and lowest for the most stable (Figure 2). The PPIA and TBP combination was by far the most stable and $18 \mathrm{~s}$ rRNA was the least stable reference gene (Figure 2).

For the combination of all four conditions, N1+N14 + Hyper14+Hypo14, NormFinder also selected PPIA and 
Table 2 Ranking of the 6 selected reference genes in rat whole carotid bodies by geNorm, NormFinder and BestKeeper

\begin{tabular}{|c|c|c|c|c|c|c|c|c|}
\hline \multirow{2}{*}{$\begin{array}{l}\text { geNorm } \\
\text { Rank }\end{array}$} & \multicolumn{2}{|c|}{$\mathrm{N} 1+\mathrm{N} 14(\mathrm{n}=16)$} & \multicolumn{2}{|c|}{ N14+Hyper14 (n = 14) } & \multicolumn{2}{|c|}{ N14+Hypo14 (n = 14) } & \multicolumn{2}{|c|}{ N1+N14+Hyper14+ Hypo14 $(n=28)$} \\
\hline & Gene & M-value & Gene & M-value & Gene & M-value & Gene & M-value \\
\hline Best two genes & RPII TBP & 0.26 & PPIA TBP & 0.20 & PPIA TBP & 0.29 & PPIA TBP & 0.26 \\
\hline 3 & PPIA & 0.27 & RPII & 0.35 & RPII & 0.36 & RPII & 0.38 \\
\hline 4 & actin & 0.34 & GAPDH & 0.43 & GAPDH & 0.45 & GAPDH & 0.44 \\
\hline 5 & GAPDH & 0.38 & actin & 0.50 & actin & 0.50 & actin & 0.49 \\
\hline 6 & $18 \mathrm{~s}$ & 0.40 & $18 s$ & 0.57 & $18 s$ & 0.52 & $18 \mathrm{~s}$ & 0.53 \\
\hline Norm Finder & \multicolumn{2}{|c|}{$\mathrm{N} 1+\mathrm{N} 14(\mathrm{n}=16)$} & \multicolumn{2}{|c|}{ N14+Hyper14 $(\mathrm{n}=14)$} & \multicolumn{2}{|c|}{ N14+Hypo14 ( $n=14)$} & \multicolumn{2}{|c|}{ N1+ N14+Hyper14+ Hypo14 $(n=28)$} \\
\hline Rank & Gene & Variability & Gene & Variability & Gene & Variability & Gene & Variability \\
\hline Best two genes & TBP Actin & 0.009 & RPII GAPDH & 0.007 & RPII GAPDH & 0.008 & PPIA TBP & 0.011 \\
\hline 1 & GAPDH & 0.01 & RPII & 0.013 & TBP & 0.007 & TBP & 0.015 \\
\hline 2 & PPIA & 0.011 & GAPDH & 0.013 & PPIA & 0.015 & GAPDH & 0.017 \\
\hline 3 & actin & 0.014 & TBP & 0.014 & GAPDH & 0.018 & $18 s$ & 0.019 \\
\hline 4 & TBP & 0.015 & actin & 0.019 & RPII & 0.018 & PPIA & 0.020 \\
\hline 5 & RPII & 0.016 & PPIA & 0.021 & $18 s$ & 0.020 & RPII & 0.021 \\
\hline 6 & $18 \mathrm{~s}$ & 0.018 & $18 \mathrm{~s}$ & 0.021 & actin & 0.021 & actin & 0.023 \\
\hline Best Keeper & \multicolumn{2}{|c|}{$\mathrm{N} 1+\mathrm{N} 14(\mathrm{n}=16)$} & \multicolumn{2}{|c|}{ N14+ yper14 $(n=14)$} & \multicolumn{2}{|c|}{ N14+Hypo14 (n = 14) } & \multicolumn{2}{|c|}{$\mathrm{N} 1+\mathrm{N} 14+$ Hyper14+ Hypo14 $(\mathrm{n}=28)$} \\
\hline Rank & Gene & Coeff. of corr.[r] & Gene & Coeff. of corr.[r] & Gene & Coeff. of corr.[r] & Gene & Coeff. of corr.[r] \\
\hline 1 & PPIA & 0.89 & RPII & 0.97 & RPII & 0.86 & PPIA & 0.97 \\
\hline 2 & actin & 0.84 & PPIA & 0.96 & PPIA & 0.85 & TBP & 0.95 \\
\hline 3 & GAPDH & 0.83 & GAPDH & 0.96 & TBP & 0.85 & GAPDH & 0.95 \\
\hline 4 & $18 \mathrm{~s}$ & 0.73 & TBP & 0.95 & actin & 0.75 & RPII & 0.93 \\
\hline 5 & RPII & 0.72 & actin & 0.93 & GAPDH & 0.69 & actin & 0.92 \\
\hline 6 & TBP & 0.70 & $18 s$ & 0.87 & $18 s$ & 0.56 & $18 s$ & 0.89 \\
\hline
\end{tabular}

The reference genes are ranked in several groups of $\mathrm{CB}$ as follows: $\mathrm{N} 1+\mathrm{N} 14=$ immature and mature $\mathrm{CB}$, reared in normoxia $(\mathrm{n}=16)$. N14+Hyper14 = mature normoxia and hyperoxia treated $C B(n=14)$. N14+Hypo14 = mature normoxia and hypoxia treated $C B(n=14) . N 1+N 14+H y p e r 14+H y p o 14=$ immature, normoxia (N1), mature, normoxia (N14), mature, hyperoxia (Hyper14), and mature, hypoxia treated (Hypo14) CB ( $n=28)$. Genes are ranked on their stability value calculated by each respective program: geNorm, M-value; NormFinder, Variability; and BestKeeper, Coefficient of correlation [r]. ( $\mathrm{n}$ ) = number of independent determinations.

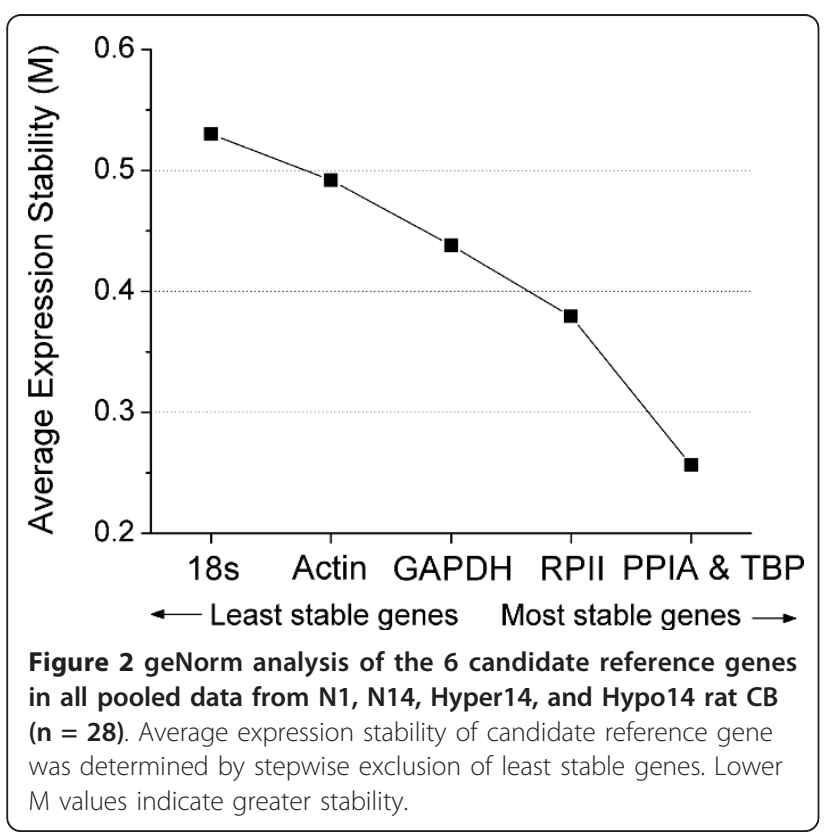

TBP as the best two reference genes (Table 2) and BestKeeper ranked PPIA and TBP as the top two most stable reference genes (Table 2). Rankings for other combinations of conditions varied more with NormFinder and BestKeeper, compared to geNorm (Table 2). Similar to the $18 \mathrm{~s}$ rankings produced by geNorm, $18 \mathrm{~s}$ rRNA tended to rank near the bottom of stability rankings using NormFinder and BestKeeper (Table 2).

As the three programs produced different results, we attempted to determine consensus rankings using weighted rank aggregation. The most consistent result of consensus rankings was that 18s rRNA ranked at or near the bottom of the rankings under all conditions (Table 3). For development alone (N1+N14) PPIA and GAPDH ranked as the top two reference genes by consensus analysis (Table 3). For hyperoxia during development (N14+Hyper14) RPII and TBP were ranked as the top two genes by consensus (Table 3 ). In both groups involving hypoxia during development (N14+Hypo14 and $\mathrm{N} 1+\mathrm{N} 14+$ Hyper14+Hypo14) TBP and PPIA were 
Table 3 Consensus ranking

\begin{tabular}{|c|c|c|c|c|}
\hline \multicolumn{5}{|c|}{ Gene ranking for group $\mathrm{N} 1+\mathrm{N} 14(\mathrm{n}=16)$} \\
\hline Rank Position & geNorm & NormFinder & BestKeeper & Consensus \\
\hline 1 & RP\| & GAPDH & PPIA & PPIA \\
\hline 2 & TBP & PPIA & Actin & GAPDH \\
\hline 3 & PPIA & Actin & GAPDH & Actin \\
\hline 4 & Actin & TBP & $18 s$ & RPII \\
\hline 5 & GAPDH & RPII & RPII & TBP \\
\hline 6 & $18 \mathrm{~s}$ & $18 \mathrm{~s}$ & TBP & $18 \mathrm{~s}$ \\
\hline \multicolumn{5}{|c|}{ Gene ranking for group N14+Hyper14 $(n=14)$} \\
\hline Rank Position & geNorm & NormFinder & BestKeeper & Consensus \\
\hline 1 & PPIA & RPII & RPII & RPII \\
\hline 2 & TBP & GAPDH & PPIA & TBP \\
\hline 3 & RPII & TBP & GAPDH & GAPDH \\
\hline 4 & GAPDH & Actin & TBP & PPIA \\
\hline 5 & Actin & PPIA & Actin & Actin \\
\hline 6 & $18 \mathrm{~s}$ & $18 \mathrm{~s}$ & $18 \mathrm{~s}$ & $18 \mathrm{~s}$ \\
\hline \multicolumn{5}{|c|}{ Gene ranking for group N14+Hypo14 $(n=14)$} \\
\hline Rank Position & geNorm & NormFinder & BestKeeper & Consensus \\
\hline 1 & PPIA & TBP & RPII & TBP \\
\hline 2 & TBP & PPIA & PPIA & PPIA \\
\hline 3 & RPII & GAPDH & TBP & RPII \\
\hline 4 & GAPDH & RPII & Actin & GAPDH \\
\hline 5 & Actin & $18 \mathrm{~s}$ & GAPDH & Actin \\
\hline 6 & $18 \mathrm{~s}$ & Actin & $18 \mathrm{~s}$ & $18 \mathrm{~s}$ \\
\hline \multicolumn{5}{|c|}{ Gene ranking for group N1+N14+Hyper14+Hypo14 $(n=28)$} \\
\hline Rank Position & geNorm & NormFinder & BestKeeper & Consensus \\
\hline 1 & PPIA & TBP & PPIA & TBP \\
\hline 2 & TBP & GAPDH & TBP & PPIA \\
\hline 3 & RPII & $18 \mathrm{~s}$ & GAPDH & GAPDH \\
\hline 4 & GAPDH & PPIA & RPII & RPII \\
\hline 5 & Actin & RPII & Actin & $18 \mathrm{~s}$ \\
\hline 6 & $18 \mathrm{~s}$ & Actin & $18 s$ & Actin \\
\hline
\end{tabular}

Weighted rank aggregation was performed to combine the ordered lists of genes produced by geNorm, NormFinder, and BestKeeper to a consensus rank of genes.

ranked, by consensus, as the top two most stable reference genes (Table 3). When the group included hyperoxia or hypoxia during development, actin ranked at or near the bottom of stability rankings (Table 3 ).

Another potential source of variability is the source of the qPCR master mixture. Therefore, the six reference genes were tested with iQ SYBR green supermix from Bio-Rad and compared with PCR master mix from Applied Biosystems, using geNorm, NormFinder and BestKeeper (Table 4). Overall, the Applied Biosystems SYBR green mastermix provided more consistent rankings across the three software programs. However, in spite of the greater variability in rankings in the Bio-Rad group, the consensus rankings were nearly identical for the two different vendors (Table 4).
The impact of reference gene choice was evaluated by determining the relative gene expression ratios of three relevant targets during $C B$ development, genes for TASK-1, TASK-2 and TASK-3 potassium channels. Their relative expression during development was evaluated with REST2009 (http://www.gene-quantification.de/ rest-2009.html) using the stable combination PPIA and TBP, as determined by geNorm, vs. the least stable reference gene, 18s rRNA. As shown in table 5, TASK-2 expression was found to be significantly down-regulated during development when PPIA+TBP were the reference genes, but not when 18s rRNA was used as a reference gene.

\section{Discussion}

We investigated the expression stability in rat whole carotid body of multiple commonly used qPCR reference genes, during early postnatal development when rat $\mathrm{CB} \mathrm{O}_{2}$-sensing maturation takes place [10-12,36,37], using three popular software programs for reference gene selection as well as qPCR reagents from different vendors. Although the three programs produced similar results, the rankings were not identical and, in some cases, were substantially different. With respect to agreement between the three programs, for the combination of all conditions (N1+N14+Hyper14+Hypo14) geNorm and NormFinder selected PPIA+TBP as the best combination of multiple reference genes and BestKeeper selected PPIA and TBP as the two highest ranked (more stable) reference genes. The results indicated that 18s rRNA was the least stable reference gene for $\mathrm{CB}$ overall and, when hyperoxia and/or hypoxia conditions are included, actin was similarly unstable. The use of reagents from different vendors may substantially impact reference gene stability rankings.

geNorm produced the most consistent results across all developmental/oxygen conditions, selecting PPIA + TBP as the best multiple reference gene combination in three of four groups (Table 2). The M-value for the multiple reference gene combination PRII+TBP, selected by geNorm for $\mathrm{N} 1+\mathrm{N} 14$, is very close to that for PPIA, suggesting that PPIA+TBP would be a good choice of reference genes for all groups (Table 2).

Although our study was not designed to measure the effect of altered oxygen environment on individual reference gene expression, it appears that hyperoxia and hypoxia affect the stability rankings of specific genes. For example, NormFinder ranked actin as one of the best two reference genes for $\mathrm{N} 1+\mathrm{N} 14$, while actin was ranked as the least stable reference gene for the two groups that included chronic hypoxia (Table 2). Similarly, BestKeeper ranked actin as one of the most stable reference genes for development $(\mathrm{N} 1+\mathrm{N} 14)$, while actin was ranked among the least stable in the groups that 
Table 4 Gene ranking and consensus ranking using SYBR green super mixtures from two different vendors, Bio-Rad and Applied Biosystems

\begin{tabular}{|c|c|c|c|c|c|c|c|}
\hline \multirow[b]{3}{*}{ Rank Position } & \multicolumn{7}{|c|}{ Gene and consensus ranking for group N1+N14 $(n=16)$ using Bio-Rad SYBR } \\
\hline & \multicolumn{7}{|c|}{ Bio-Rad SYBR } \\
\hline & geNorm & M-value & NormFinder & Variability & BestKeeper & Coeff. of corr. [r] & Consensus \\
\hline 1 & TBP & 0.26 & GAPDH & 0.01 & PPIA & 0.89 & PPIA \\
\hline 2 & RPII & 0.26 & PPIA & 0.011 & Actin & 0.84 & GAPDH \\
\hline 3 & PPIA & 0.27 & Actin & 0.014 & GAPDH & 0.83 & Actin \\
\hline 4 & Actin & 0.34 & TBP & 0.015 & $18 \mathrm{~s}$ & 0.73 & TBP \\
\hline 5 & GAPDH & 0.38 & RPII & 0.016 & RPII & 0.72 & RPII \\
\hline 6 & $18 \mathrm{~s}$ & 0.40 & $18 \mathrm{~s}$ & 0.018 & TBP & 0.70 & $18 \mathrm{~s}$ \\
\hline
\end{tabular}

\begin{tabular}{|c|c|c|c|c|c|c|c|}
\hline \multirow[b]{3}{*}{ Rank Position } & \multicolumn{7}{|c|}{ Gene and consensus ranking for group N1 + N14 $(n=16)$ using Applied Biosystems SYBR } \\
\hline & \multicolumn{7}{|c|}{ Applied Biosystems SYBR } \\
\hline & geNorm & M-value & NormFinder & Variability & BestKeeper & Coeff. of corr. [r] & Consensus \\
\hline 1 & PPIA & 0.21 & PPIA & 0.008 & PPIA & 0.99 & PPIA \\
\hline 2 & GAPDH & 0.21 & GAPDH & 0.013 & GAPDH & 0.99 & GAPDH \\
\hline 3 & Actin & 0.25 & Actin & 0.013 & Actin & 0.99 & Actin \\
\hline 4 & RPII & 0.32 & RPII & 0.014 & RPII & 0.98 & RPII \\
\hline 5 & TBP & 0.34 & TBP & 0.016 & TBP & 0.98 & TBP \\
\hline 6 & $18 \mathrm{~s}$ & 0.39 & $18 \mathrm{~s}$ & 0.024 & $18 \mathrm{~s}$ & 0.97 & $18 \mathrm{~s}$ \\
\hline
\end{tabular}

The reference genes are ranked for N1+N14 group by geNorm, Normfinder and BestKeeper and the consensus ranking determined by rank aggregation. (n) = number of independent determinations.

included chronic hyperoxia or hypoxia (Table 2). Thus, the effect of hypoxia on housekeeping gene expression may vary with experimental conditions and should be tested for a given tissue and set of conditions. We did not investigate the effects of chronic intermittent hypoxia $(\mathrm{CIH})$ on reference gene stability because there are many different $\mathrm{CIH}$ exposure paradigms and such a large undertaking was beyond the scope of the present study.

An obvious potential limitation of this study is that better combinations of reference genes may exist, for the study of rat CB development, beyond the ones chosen. The choice of the six candidate reference genes studied was based on their common use and evidence that they are stable so-called "housekeeping genes" in other

Table 5 Relative gene expression ratios of three interest TASK channel genes, TASK-1, TASK-2, and TASK-3, were compared by using one least stable reference gene (18s rRNA) and two best stable reference genes (PPIA and TBP)

\begin{tabular}{cccc}
\hline Reference Gene & $\begin{array}{c}\text { TASK-1 } \\
(\boldsymbol{p} \text { value, } \mathrm{n})\end{array}$ & $\begin{array}{c}\text { TASK-2 } \\
(\boldsymbol{p} \text { value, } \mathrm{n})\end{array}$ & $\begin{array}{c}\text { TASK-3 } \\
(\boldsymbol{p} \text { value, } \mathrm{n})\end{array}$ \\
\hline 18s rRNA & 1.172 & 0.682 & 1.285 \\
& $(0.756, \mathrm{n}=11)$ & $(0.442, \mathrm{n}=8)$ & $(0.661, \mathrm{n}=12)$ \\
\hline PPIA \& TBP & 0.69 & 0.29 & 0.925 \\
& $(0.183, \mathrm{n}=13)$ & $(0.000, \mathrm{n}=11)$ Down & $(0.545, \mathrm{n}=13)$
\end{tabular}

The ratios and statistical $p$ values of three interest genes in groups $\mathrm{N} 1+\mathrm{N} 14$ were analyzed by REST2009 software. $(n)=$ number of independent determinations. tissues. Never-the-less, others may exist that will turn out to be equally or more stable and suitable for developmental carotid body studies.

Our results add to a growing body of literature showing that reference or housekeeping gene expression for qPCR may vary with developmental stage and environmental conditions, and the specific genes, pattern and timing of variation may be tissue-specific [38]. It is also important to consider that our results are likely to be species-specific and may be developmental time-frame specific; studies of carotid body maturation in other species should validate reference genes for each species, $\mathrm{O}_{2}$ conditions and developmental time-frame.

\section{Acknowledgements}

This study was supported by NIH grant 5R01HL054621.

\section{Author details}

${ }^{1}$ University of Arkansas for Medical Sciences, Department of Pediatrics, Division of Pulmonary Medicine, Arkansas Children's Hospital Research Institute, Little Rock, Arkansas, USA. ${ }^{2}$ University of Arkansas for Medical Sciences, Department of Pediatrics, Division of Biostatistics, Arkansas Children's Hospital Research Institute, Little Rock, Arkansas, USA.

\section{Authors' contributions}

IK participated in study concept and design, carried out the qPCR studies and participated in drafting the manuscript. DY helped with the qPCR studies. XT performed rank aggregation statistical analysis and participated in writing the manuscript. JC participated in study concept, design and drafting the manuscript. All authors read and approved the final manuscript.

\section{Competing interests}

Statement for all authors: 
The authors declare that they have no competing interests.

Received: 29 June 2010 Accepted: 24 October 2011

Published: 24 October 2011

\section{References}

1. Marshall JM: Peripheral chemoreceptors and cardiovascular regulation. Physiol Rev 1994, 74:543-594.

2. Bureau MA, Lamarche J, Foulon P, Dalle D: Postnatal maturation of respiration in intact and carotid body-chemodenervated lambs. J Appl Physiol 1985, 59:869-874

3. Bureau MA, Lamarche J, Foulon P, Dalle D: The ventilatory response to hypoxia in the newborn lamb after carotid body denervation. Respir Physiol 1985, 60:109-119.

4. Fewell JE, Taylor BJ, Kondo CS, Dascalu V, Filyk SC: Influence of carotid denervation on the arousal and cardiopulmonary responses to upper airway obstruction in lambs. Pediatr Res 1990, 28:374-378.

5. Fewell JE, Kondo CS, Dascalu V, Filyk SC: Influence of carotid-denervation on the arousal and cardiopulmonary responses to alveolar hypercapnia in lambs. J Dev Physiol 1989, 12:193-199.

6. Fewell JE, Kondo CS, Dascalu V, Filyk SC: Influence of carotid denervation on the arousal and cardiopulmonary response to rapidly developing hypoxemia in lambs. Pediatr Res 1989, 25:473-477

7. Carroll $\mathrm{J}$, Donnelly DF: Postnatal development of Carotid Chemoreceptor Function. In Sleep and Breathing in Children: Developmental Changes in Breathing During Sleep. Edited by: Marcus CL, Carroll, J.L., Donnelly, D.F. New York: Informa Healthcare; 2008:47-82.

8. Carroll JL, Kim I: Postnatal development of carotid body glomus cell $\mathrm{O} 2$ sensitivity. Respir Physiol Neurobiol 2005, 149:201-215.

9. Gonzalez C, Almaraz L, Obeso A, Rigual R: Carotid body chemoreceptors: from natural stimuli to sensory discharges. Physiol Rev 1994, 74:829-898.

10. Wasicko MJ, Breitwieser GE, Kim I, Carroll JL: Postnatal development of carotid body glomus cell response to hypoxia. Respir Physiol Neurobiol 2006, 154:356-371.

11. Bamford OS, Sterni LM, Wasicko MJ, Montrose MH, Carroll JL: Postnatal maturation of carotid body and type I cell chemoreception in the rat. Am J Physiol 1999, 276:L875-884.

12. Wasicko MJ, Sterni LM, Bamford OS, Montrose MH, Carroll JL: Resetting and postnatal maturation of oxygen chemosensitivity in rat carotid chemoreceptor cells. J Physiol 1999, 514(Pt 2):493-503.

13. Zhong $\mathrm{H}$, Simons JW: Direct comparison of GAPDH, beta-actin, cyclophilin, and 28S rRNA as internal standards for quantifying RNA levels under hypoxia. BiochemBiophysResCommun 1999, 259:523-526.

14. Thellin O, Zorzi W, Lakaye B, De BB, Coumans B, Hennen G, Grisar T, Igout A, Heinen E: Housekeeping genes as internal standards: use and limits. J Biotechnol 1999, 75:291-295.

15. Schmittgen TD, Zakrajsek BA: Effect of experimental treatment on housekeeping gene expression: validation by real-time, quantitative RTPCR. J BiochemBiophysMethods 2000, 69-81, \%20;46.

16. Suzuki T, Higgins PJ, Crawford DR: Control selection for RNA quantitation. Biotechniques 2000, 29:332-337.

17. Goidin D, Mamessier A, Staquet MJ, Schmitt D, Berthier-Vergnes O: Ribosomal 18S RNA prevails over glyceraldehyde-3-phosphate dehydrogenase and beta-actin genes as internal standard for quantitative comparison of mRNA levels in invasive and noninvasive human melanoma cell subpopulations. AnalBiochem 2001, 295:17-21.

18. Selvey S, Thompson EW, Matthaei K, Lea RA, Irving MG, Griffiths LR: Betaactin-an unsuitable internal control for RT-PCR. MolCell Probes 2001, 15:307-311.

19. Robert C, McGraw S, Massicotte L, Pravetoni M, Gandolfi F, Sirard MA: Quantification of housekeeping transcript levels during the development of bovine preimplantation embryos. Bio/Reprod 2002, 67:1465-1472.

20. Dheda K, Huggett JF, Bustin SA, Johnson MA, Rook G, Zumla A: Validation of housekeeping genes for normalizing RNA expression in real-time PCR. Biotechniques 2004, 37:112-119.

21. Huggett J, Dheda K, Bustin S, Zumla A: Real-time RT-PCR normalisation; strategies and considerations. Genes Immun 2005, 6:279-284.

22. Vandesompele J, De PK, Pattyn F, Poppe B, Van RN, De PA, Speleman F: Accurate normalization of real-time quantitative RT-PCR data by geometric averaging of multiple internal control genes. Genome Biol 2002, 3:RESEARCH0034.

23. Goossens K, Van PM, Van SA, Vandesompele J, Van ZA, Peelman LJ: Selection of reference genes for quantitative real-time $P C R$ in bovine preimplantation embryos. BMCDevBiol 2005, 5:27:27.

24. Ohl F, Jung M, Xu C, Stephan C, Rabien A, Burkhardt M, Nitsche A, Kristiansen G, Loening SA, Radonic A, Jung K: Gene expression studies in prostate cancer tissue: which reference gene should be selected for normalization? J MolMed 2005, 83:1014-1024.

25. Andersen $C L$, Jensen $J$, Orntoft TF: Normalization of real-time quantitative reverse transcription-PCR data: a model-based variance estimation approach to identify genes suited for normalization, applied to bladder and colon cancer data sets. Cancer Res 2004, 64:5245-5250.

26. Pfaffl MW, Tichopad A, Prgomet C, Neuvians TP: Determination of stable housekeeping genes, differentially regulated target genes and sample integrity: BestKeeper-Excel-based tool using pair-wise correlations. Biotechnol Lett 2004, 26:509-515.

27. Brouillette RT, Waxman DH: Evaluation of the newborn's blood gas status. National Academy of Clinical Biochemistry. ClinChem 1997, 43:215-221.

28. Acharya $G$, Sitras $V$ : Oxygen uptake of the human fetus at term. Acta ObstetGynecolscand 2008, 1-6.

29. Carroll JL: Developmental plasticity in respiratory control. J ApplPhysiol 2003, 94:375-389.

30. Haddad JJ: Oxygen-sensing mechanisms and the regulation of redoxresponsive transcription factors in development and pathophysiology. RespirRes 2002, 3:26.

31. Fink $T$, Lund $P$, Pilgaard $L$, Rasmussen JG, Duroux $M$, Zachar $V$ : Instability of standard PCR reference genes in adipose-derived stem cells during propagation, differentiation and hypoxic exposure. BMC Mol Biol 2008 9:98.

32. Pfaffl MW: A new mathematical model for relative quantification in realtime RT-PCR. Nucleic Acids Res 2001, 29:e45.

33. Pfaffl MW, Horgan GW, Dempfle L: Relative expression software tool (REST) for group-wise comparison and statistical analysis of relative expression results in real-time PCR. Nucleic Acids Res 2002, 30:e36.

34. Mallona I, Lischewski S, Weiss J, Hause B, Egea-Cortines M: Validation of reference genes for quantitative real-time PCR during leaf and flower development in Petunia hybrida. BMC Plant Biol 2010, 10:4.

35. Pihur $V$, Datta S: RankAggreg, an $R$ package for weighted rank aggregation. BMC Bioinformatics 2009, 10:62.

36. Donnelly DF, Doyle TP: Developmental changes in hypoxia-induced catecholamine release from rat carotid body, in vitro. J Physiol 1994 475:267-275.

37. Kholwadwala D, Donnelly DF: Maturation of carotid chemoreceptor sensitivity to hypoxia: in vitro studies in the newborn rat. J Physio/ 1992, 453:461-473.

38. van Wijngaarden $\mathrm{P}$, Brereton HM, Coster DJ, Williams KA: Stability of housekeeping gene expression in the rat retina during exposure to cyclic hyperoxia. MolVis 2007, 13:1508-1515.

doi:10.1186/1756-0500-4-440

Cite this article as: Kim et al:: Reference gene validation for qPCR in rat carotid body during postnatal development. BMC Research Notes 2011 4:440.

\section{Submit your next manuscript to BioMed Central and take full advantage of:}

- Convenient online submission

- Thorough peer review

- No space constraints or color figure charges

- Immediate publication on acceptance

- Inclusion in PubMed, CAS, Scopus and Google Scholar

- Research which is freely available for redistribution 